\title{
Computing the Variation of Stream Flow in a Gauged Basin using Satellite Imagery with Regards To Change in Land Use Pattern
}

\author{
Amruth Chand B, Varija K \\ Department of Applied Mechanics \& Hydraulics, NITK, Surathkal, India
}

\begin{abstract}
Hydrological and water resource problems always pose a serious challenge to mankind from time immemorial. The ambiguity in data, its non-availability, error in measurement of data's, unconditional ground characteristics always has been a challenge to hydraulic engineers. The watershed characteristics and studies also pose the same problems. Conventional rain-fall measuring techniques, non-reliable gauge and discharge data, etc add to these problems. Over the development of remote sensing techniques, hydraulics engineers too started to use these techniques over water related problem. In this paper, the remote sensing technique is used in computing the effect of land use change in a river basin in Dakshina Kannada district of Karnataka, India and then the effects of these changes on the streamflow of the same river is analysed. With the development of a suitable numerical model, the same can be used to compute the runoff characteristics in any un-gauged basin too. With the scarcity of water resource data and the difficulty in obtaining them, the best way to address water related problems of the future is too shift to these remote sensing techniques. The satellite imagery for the study purpose has been obtained from IRS satellites and Bhuvan data portal. The runoff and rainfall data has been obtained from Indian meteorological department and Karnataka Irrigation department. Once the change in land use pattern is analysed and the corresponding change in runoff pattern is computed, suitable measures can be taken to overcome the drastic hydrological changes in the basin and remedial measures can be taken.
\end{abstract}

Keywords: Remote Sensing, Stream flow, Land use.

\section{Introduction}

Farming and cultivation has become a commercial feature nowadays compared to the earlier times. Farmers have shifted from rice and paddy cultivation to cash crops like rubber and areca nut. This has caused a drastic change in cultivation pattern thereby in the land use pattern too. The built up area, especially near the towns, have considerably increased over the past years. Human encroachment into forest is also increasing resulting in deforestation. The change in agricultural practice, deforestation, change in built up area etc., affects adversely on the infiltration characteristics of the soil. Studies have contributed to the fact that thastic change in forest area may adversely affect the runoff characteristic of rivers and lead to high flow during monsoon and draught during summer time. The quantification of these factors was not presented in both studies.

A reduction in infiltration means an increase in runoff. The rainwater after falling on earth surface flows directly into the rivers without ponding for infiltration. This phenomenon increases the peak flow in the rivers and decreases the ground water resources in the basins. Most of the summer flows in rivers are from ground water resources. Due to depletion in ground water resources, the summer flow considerably decreases in rivers. About $90 \%$ of land surface of the earth is covered by vegetation of some kind or the other. There is an increasing need to precisely describe and classify land uses and land covers in order to define sustainable land use system that are best suited. The land use must match the carrying capacity of land for sustainable production and environmental change detection. Availability of remote sensing data from earth observation satellites has made it convenient to map and monitor land use/ land cover at regional to local scales. A land cover map is very critical for various planning activities including watershed planning. Due to human activities, land use pattern in and around watershed has been changing- the built up area has been increasing, forest area has been decreasing etc.

Stephane Savary, et al. (2009) developed a methodology to assess the potential hydrological response of the Chaudiere River watershed to historical land cover changes. Bhutiyani (2009) analysed the trend in stream flow patterns in the rivers of northwestern Himalayas as an implication of global warming in the $20^{\text {th }}$ century. Simone Giertz and Gero steup (2006) analyzed and studied the effect of Land use Land cover changes on the water cycle.

Thus the change in land use/land cover pattern has two adverse effects on the water shed system. It increases the peak flow in river and decreases the summer flow in the rivers. Hence a study on the effect of land use/land cover pattern on the runoff characteristics is essential to know these impacts on the basin. 
The study involves the following:

\section{Objectives and Methodology}

a) Trend analysis of runoff in the basin.

b) Quantifying the Land use/Land cover change in the basin.

c) Analysing the variation of runoff characteristics and the effect of LU/LC change in them.

The changes in land use/land cover were studied using GIS and Remote sensing techniques. Toposheets of scale 1:25000 are used to study the land use/land cover pattern in 1989 and IRS 1C/1D LISS III images of resolution $23.5 \mathrm{~m}$ are used to study the land use/land cover during the past few years. Thus the changes that occurred during the past 15 years were quantified. The methodology for the entire study and for the preparation of maps from satellite images is given in Fig.1.

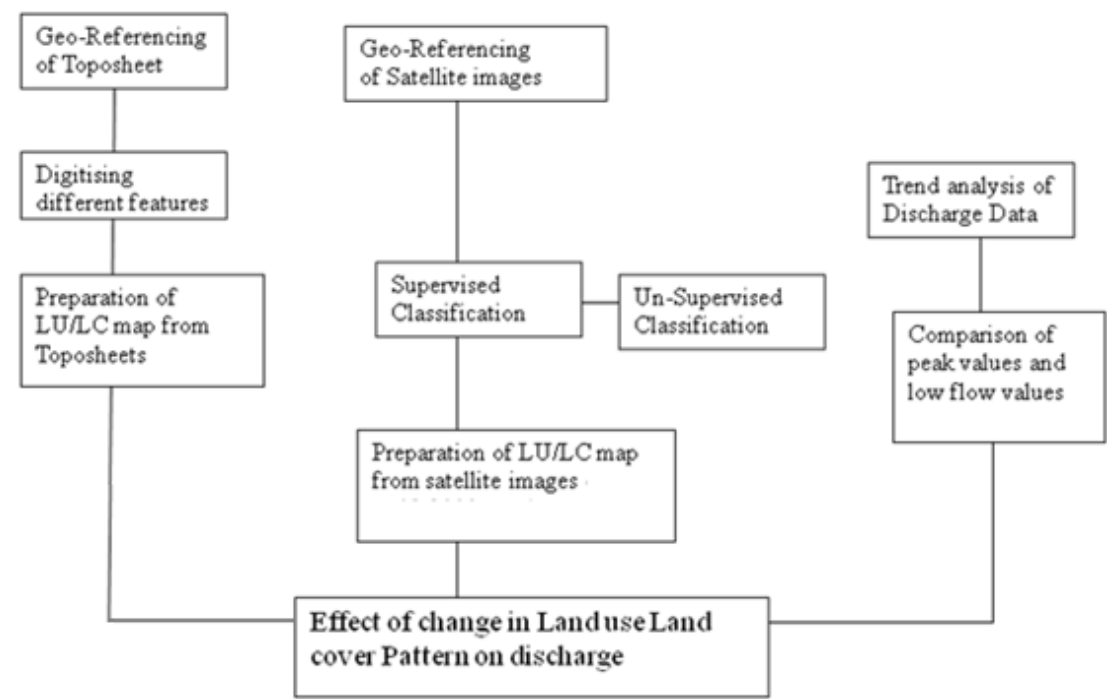

Figure 1 Flow chart of the various steps used in this study in a systematic form.

The runoff characteristics were studied by using the monthly runoff data at the outlet of the study area. About 10-15 years of peak and low flow monthly data were used for the study. The trend analysis of the runoff at the basin has to be studied. The change in land use / land cover pattern then obtained has to be compared and studied with the trend in runoff and then the effect of land use / land cover change in runoff has to be obtained.

\section{Trend Analysis of Runoff data}

The area selected for the study is the Pavanje River Basin which lies between 12'57'30 N to 13'07'30 $\mathrm{N}$ latitudes and $74^{\prime} 45^{\prime} \mathrm{E}$ to $75^{\prime} 02^{\prime} 30 \mathrm{E}$ longitude and spreads over the Dakshina Kannada districts of Karnataka state, India. The Pavanje River originates in the foothills of Western Ghats and flows towards west to join the Arabian Sea. The area of catchment is 202.33Sq.Km. Fig 2 shows the location of the study area- Pavanje River Basin.

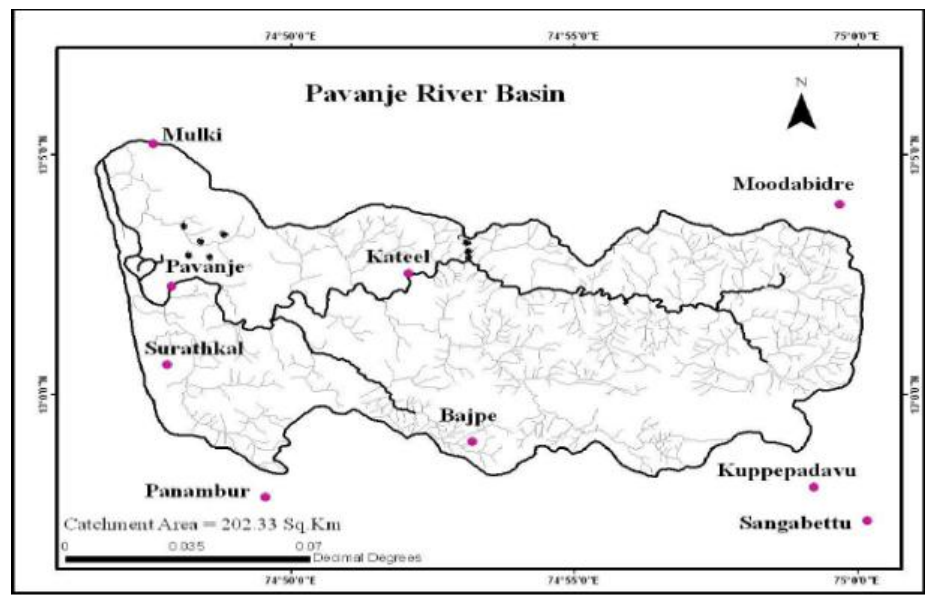

Figure 2 Location of the study area- Pavanje River Basin 
Seasonality, flow related missing values, non-normal distribution, values below the limit of detection etc are some of the characteristics that complicate hydrological analysis. Stochastic methods- Mann-Kendall, Sen's slope etc are the various methods to compare and analyse trend change. Mann-Kendall uses relative ranking of the data (not on data itself), Theil-Sen estimator is a non-parametric method to estimate a slope which is resistant to the presence of outliers (extremely variant data values) which can wreak havoc with least-squares regression. It also doesn't rely on the noise following the normal distribution. In this case, we use a linear trend analysis of simple study of the data. Runoff trend of a basin has to be studied to know the changes that occur in the discharge of a basin. The trend analysis of discharge data was obtained by studying the variation of peak discharge and low flows over the period of study. Variation of annual peak discharge against time, annual minimum discharge against time, comparison of hydrographs in 1990 to that of in 2012, average daily discharge for five years with time from 1990 to 1995 and from 2008 to 2012, five years moving average for high flow and low flows were determined. Relations were established between rainfall and runoff for different periods and were compared.

\subsection{Annual Maximum and Annual Minimum Discharge}

The changes that might have occurred in the river basin over the past period may create a corresponding change in the discharge values. In order to study the changes, the annual flood peak values and annual low flow values are selected. The discharge values for each year were sorted in the decreasing order of magnitude and a graph was plotted to analyze the change in variation of peak discharge values and low discharge values. Fig.3 shows the variation of Yearly Maximum Discharge and Yearly Minimum Discharge over the years.

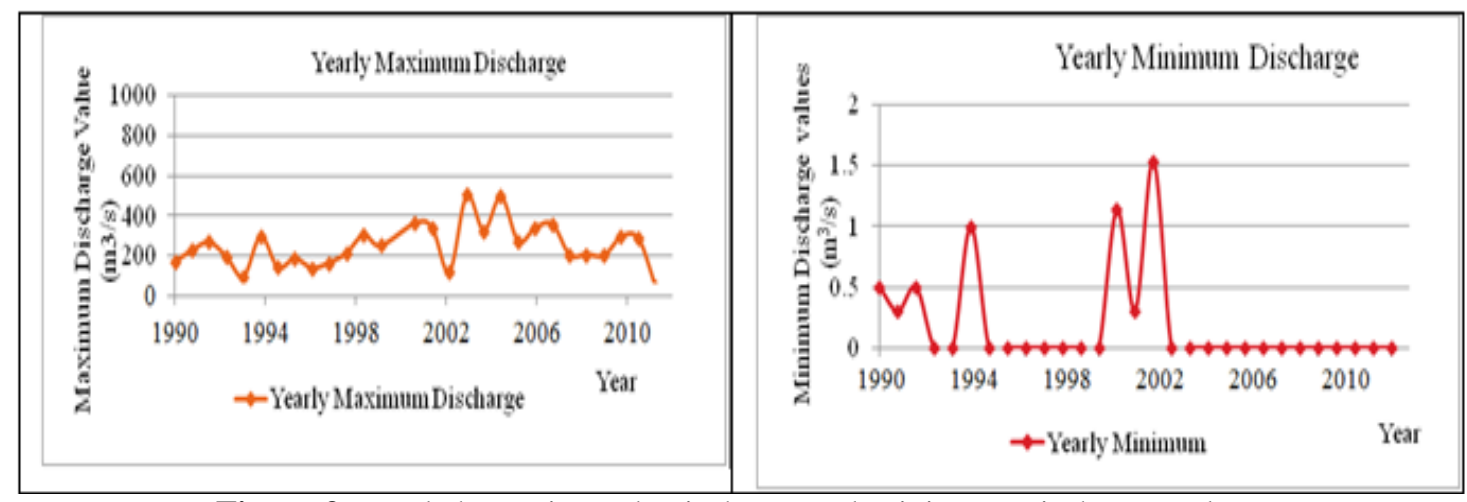

Figure 3 Trend change in Peak Discharge and Minimum Discharge Values

\subsection{Five year Moving Average Hydrograph}

The average peak flows and low flows of five years were taken from the beginning and the pattern is analysed and plotted in Fig.4. The graph shows an increasing trend in the average peak values, while a decreasing trend in the average low flow values. From the graph we can see that before 1995, the low flow value has never reached a zero mark. From 1995 to 2005, it has thrice reached the zero mark. But after 2005, the value is constantly been zero and never showed an increase. This indicates that the summer flow values are mostly zero after the year 2005 in Pavanje River basin.

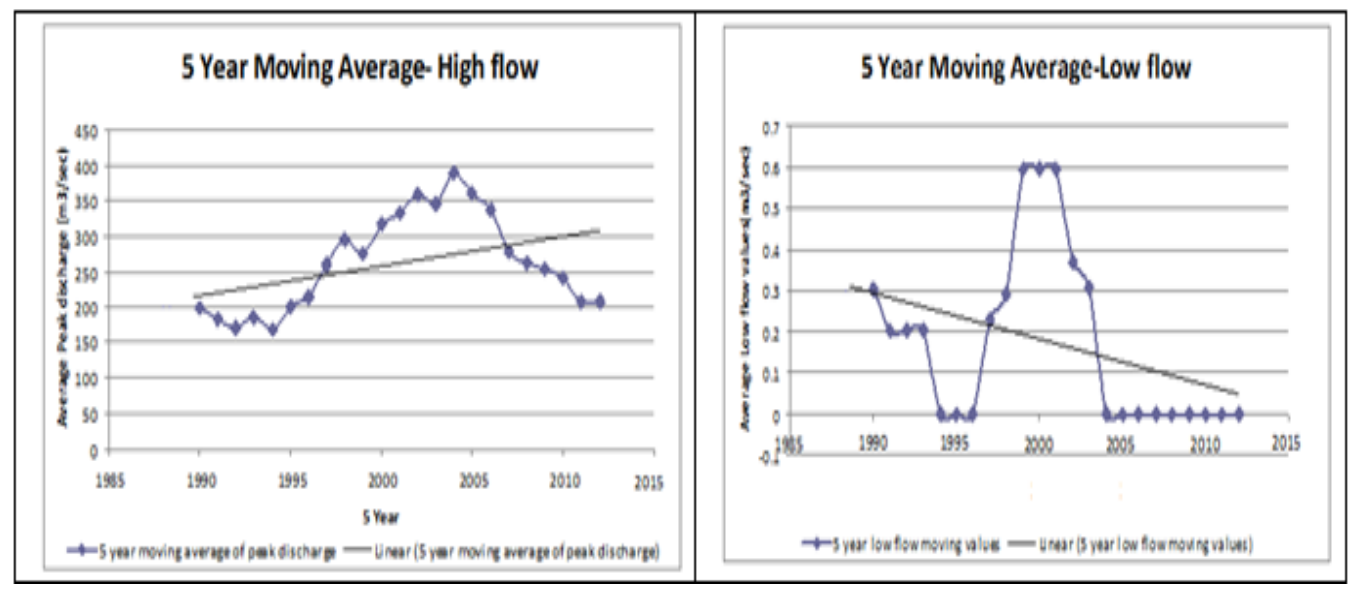

Figure 4 Five year moving Average- Peak Flow \& Low flow 


\section{Land use Land Cover Classification}

The study period selected was from 1990 to 2010. The toposheets prepared during 1989 was used to prepare Land use/Land cover map for the initial duration of study period. GIS techniques are used to classify the study area extracted from Toposheets. The Toposheets covering the study area of Pavanje river basin were identified as 48K16 SW, 48K16 SE, 48L13 NW, and 48L13NE, all 1:20,000 maps. They were then georeferenced and mosaiced. The water shed boundary was then located and digitised. The drainage network was also digitised as a feature class in the geo-database. There were seven different land use/land cover classes formed in the study area. They are water body, Hilly vegetation, Built up area, Open mixed Jungle, Rail and Roads, Palms, Bamboo and coniferous plantation and Beach areas. It was difficult to get exact built up area from toposheets because the built up areas are surrounded by vegetations or open land everywhere and was found distributed over the entire area. Hence the built up area was divided into three categories: (i) Built up area with $<10 \%$ vegetation. (ii) Built up area with $<50 \%$ vegetation. (iii) Built up area with $>50 \%$ vegetation. Table 1 gives the area under each Land use/Land cover classes in Pavanje basin derived from Toposheets and it is used as the base value of the year 1989 .

Table 1 Area under different Land use/Land covers from Toposheet 1989

\begin{tabular}{|l|l|}
\hline Land Use & Area from toposheet $\left(\mathrm{km}^{2}\right)$ \\
\hline Water body & 20.23 \\
\hline Hilly Vegetation & 27.25 \\
\hline Built up area with & 15.32 \\
\hline$<10 \%$ vegetation & 30.86 \\
\hline$<50 \%$ vegetation & 13.68 \\
\hline$>50 \%$ vegetation & 74.86 \\
\hline Total Built up area & 66.65 \\
\hline Open mixed jungle & 14.46 \\
\hline Bamboo \& conifers plantation & 12.13 \\
\hline Minor varying plantations &
\end{tabular}

\subsection{Classification from Satellite Images}

The software used is ERDAS IMAGINE 8.6. Multispectral images IRS 1C/1D LISS III for the year 2000 to 2012 are used. The full scene images of Path/Row 100/67 of IRS 1C/1D and IRS P6 covers the entire study area. The satellite images contain information in the form of pixels. Each area or land use pattern has a separate pixel value depending on its reflectance. Information is extracted from these images by studying the processed images. The system then groups all areas of similar pixel values under that category. The overall objective of image classification procedures is to automatically categorize all pixels in an image into land cover classes or themes. Normally multi spectral data are used to perform the classification and the spectral pattern present within the data for each pixel is used as the numerical basis for categorization. Table 2 shows the supervised classification images from the satellite imagery.

Table 2 Supervised Land use Land cover classification of Pavanje River Basin -2007, 2009 and 2012

\begin{tabular}{|l|l|l|l|l|}
\hline Land Use Classification & 1989 & 2007 & 2009 & 2012 \\
\hline \multicolumn{2}{|l|}{ Area in km2 } & \\
\hline Water body & 20.23 & 21.16 & 22.18 & 21.36 \\
\hline Hilly Vegetation & 27.25 & 21.36 & 20.14 & 18.46 \\
\hline Built up area with & & & & \\
\hline$<10 \%$ vegetation & 15.32 & 19.86 & 18.14 & 20.15 \\
\hline$<50 \%$ vegetation & 30.86 & 42.75 & 44.86 & 49.12 \\
\hline$>50 \%$ vegetation & 13.68 & 14.13 & 14.18 & 17.12 \\
\hline Total Built up area & 74.86 & 76.74 & 77.18 & 86.39 \\
\hline Open mixed jungle & 66.65 & 54.32 & 52.14 & 48.59 \\
\hline Bamboo \& coniferous plantation & 14.16 & 12.18 & 10.96 & 11.23 \\
\hline Minor varying plantations & 12.13 & 10.46 & 11.87 & 10.21 \\
\hline
\end{tabular}

The satellite images contain information in the form of pixels. Each area or land use pattern has a separate pixel value depending on its reflectance. Information is extracted from these images by studying the processed images. The user specifies of classifies a small portion of area or pixel under one category and similarly creates many number of classes. The system then groups all areas of similar pixel values under that category. The supervised classified satellite images of the four years are shown in Fig.5. 

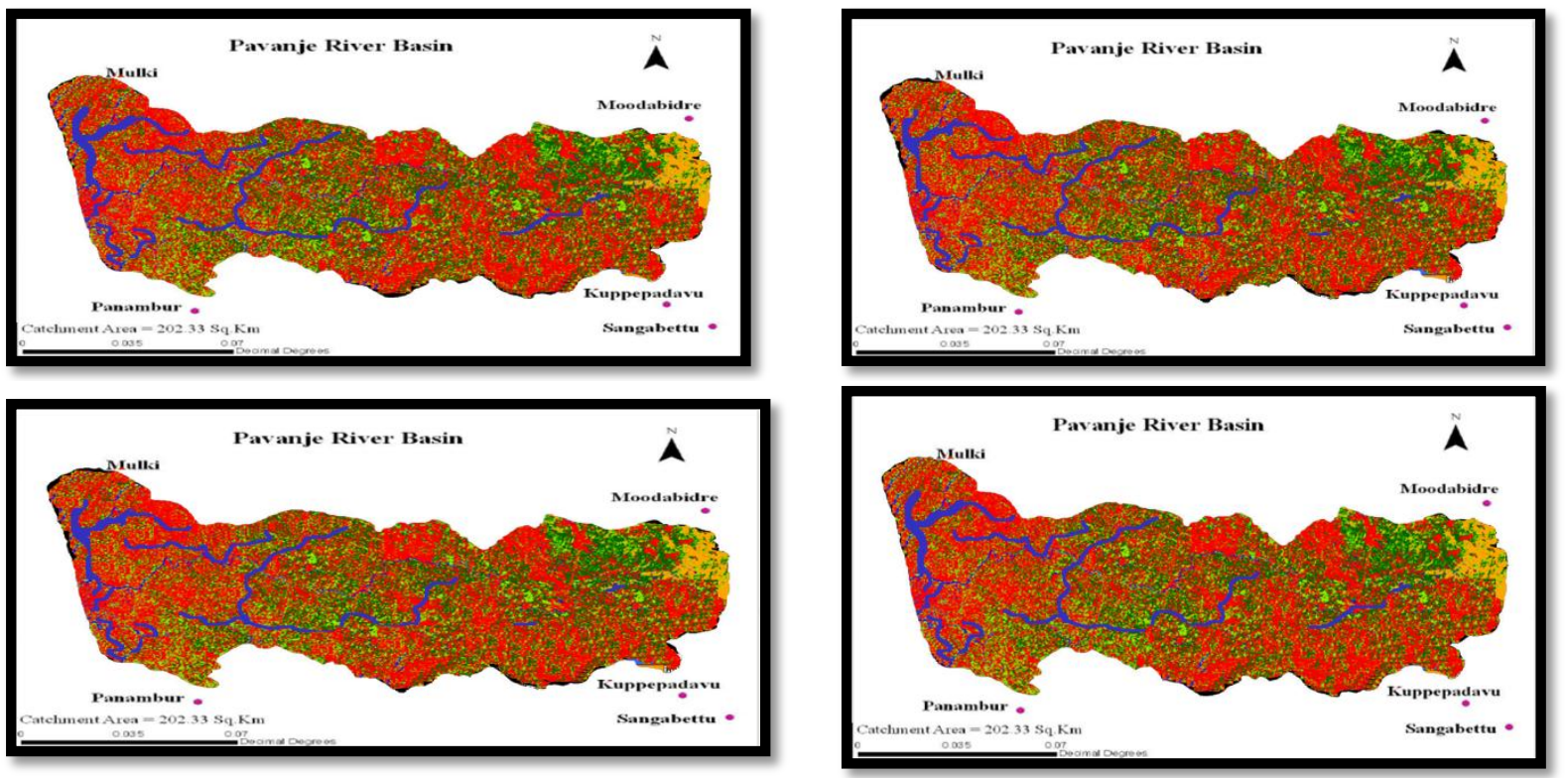

Figure 5 Supervised classification of Satellite image- 1989, 2007, 2009 and 2012

\section{Result and Discussion}

The variation of annual peak discharge over the time period showed an increase in trend which means that the general tendency of high flows is increasing year by year. The minimum flow in each year is selected and plotted against time and a trend line shows a decreasing trend. The minimum flow never reached zero before 1992. But after 2005, in every year the summer flow attained zero level.

The land use/land cover classification of the Pavanje River Basin for the year 1987 is done from toposheets and for the year 2007, 2009 and 2012 from satellite images. The built up area from toposheet was classified into three categories based on the amount of vegetation present along with the built up area as: built up with less than $10 \%$ vegetation, built up with less than $50 \%$ vegetation and built up with more than $50 \%$ vegetation. Thus the total built up area was calculated to be $74.86 \mathrm{~km} 2$. From the table 2 , it can be seen that the built up area is increasing over the course of time while the hilly vegetation and forest area have been decreasing. Fig. 6 shows the various changes in Land use over the year in Pavanje River Basin. The cultivation areas of some crops have also varied in a large extent, but the decrease in cultivation area of one crop has been balanced by the increase in cultivation area of another crop. From the graph it can be seen that the increase in built up area has been very large compared to the rise in other land use classes. A similar decreasing trend is also observed in the forest area. From the study it has been found that the $14 \%$ increase in the built up area and the $28 \%$ decrease in the forest area have contributed to the change of flow patterns in the Pavanje river basin. The trend flow of peak season shows that the increase of built up areas had major impact in the high runoff values. The draught values are almost zero indicating the drastic effect of $27 \%$ reduction in forest land. This reduction had the most impact in runoff of Pavanje River Basin.

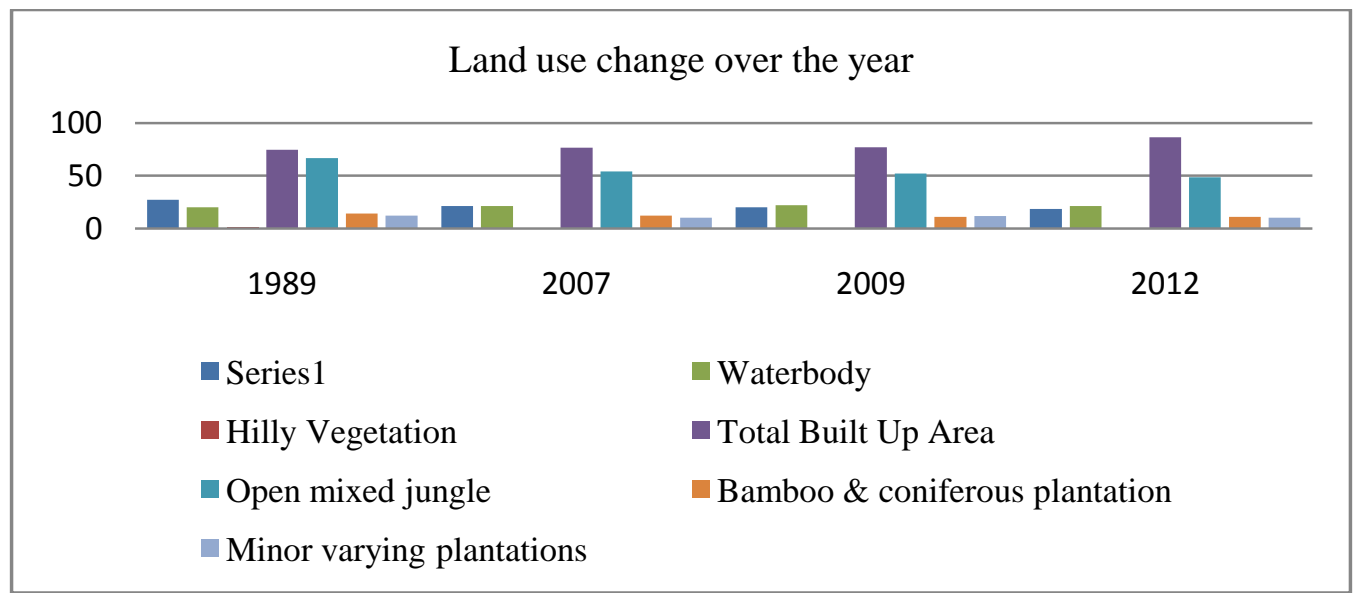

Figure 6 Various Land use /Land cover change from 1989 to 2012 


\section{Conclusions}

From the study it can be concluded that as the land use/land cover pattern over a river basin changes, the runoff of the basin is also affected or changed. The built up area over any region generally increases over the course of time as the population increases which demand more and more availability of dwelling areas. The rise in built up area means there has to be a decrease in some other land use/land cover pattern and from this study it is seen that vegetated area is cleared for this purpose. The trend analysis of the runoff at Kateel station of Pavanje River shows that the peak discharge has an increasing trend over the period of time and low flow values have a decreasing trend.

The rainfall runoff relationship derived for different periods revealed that the runoff generated from the same rainfall amounts showed an increasing trend towards the end of the period. Thus it is concluded that the increasing pattern of peak flow and the decreasing pattern of low flow values are the result of land use/land cover change. Analysis of land use/land cover pattern shows that the built up area in the Pavanje River Basin is increasing at a very high rate, while the forest area has been constantly decreasing over the period of study. The built up area increased from $74.86 \mathrm{~km} 2$ to $86.39 \mathrm{~km} 2$, i.e. a total increase of $13.39 \%$. At the same time, the forest area has decreased from $66.65 \mathrm{~km} 2$, to $48.59 \mathrm{~km} 2$, i.e. a total decrease of $27.09 \%$. Hence water shed treatment activities should be started and control measures may be adopted for checking the conversion of land use.

The present study reveals that there is an increase in trend in peak flow or monsoon flows and a decrease in trend in low flows or summer flows. It is found that the main reason behind this trend is the change in Land use/Land cover pattern. If the change in land use/land cover pattern continues at this rate, the peak flows may increase further and low lying areas may get submerged. At the same time, the river may dry up during summer season and occurrence of drought may become common. Hence water shed treatment activities should be started and control measures may be adopted for checking the conversion of land use

\section{References}

[1] Bhutiyani, M.R, "Changing stream flow pattern in the rivers of northwestern Himalayas: Implication of global warming in the 20 century, Research Article-Current science, (2006) Vol.95, pp 618-626.

[2] Simone Giertz and Gero steup, "The effect of Land use Land cover changes on the water cycle, IMPETUS Atlas Basin, 2006.

[3] Breuer, et.al., "Assessing the impact of land use change on hydrology by ensemble modelling", Journal of Hydrology, SCIENCE DIRECT, 2008, Vol-32, pp. 129-146..

[4] Stephane Savary, "Assessing the effects of Historical Land cover Changes on Runoff and Low flows using Remote sensing", Journal of Hydrology, ASCE, 2009, Vol-14, pp. 575-587.

[5] Chuanxiu Luo et.al, Effect of Land use and Land cover changes in Baoan district, China for the period 2000 to 2010., 2013, International Journal of Civil Engineering.

[6] Chirico, H. Medina, and N. Romano, "Functional evaluation of PTF prediction uncertainty: An application at hillslope scale," Geoderma, 2010, vol. 155, no. 3-4, pp. 193-202.

[7] De Silva, S. B. Weerakoon, and S. Herath, "Modeling of Event and Continuous Flow Hydrographs with HEC-HMS: Case Study in the Kelani River Basin, Sri Lanka,” J. Hydrol. Eng., 2004, vol. 19, no. 4, pp. 800-806.

[8] Pei-Jun, et al. , "The effect of land use land cover change on surface runoff in Shenzhen region, China", Journal of Hydrology, SCIENCE DIRECT, 2006, Vol-69, pp. 31-35.

[9] R. B. Jana and B. P. Mohanty, "Enhancing PTFs with remotely sensed data for multi-scale soil water retention estimation," J. Hydrol., 2011, vol. 399, no. 3-4, pp. 201-211.

[10] Stephane Savary, "Assessing the effects of Historical Land cover Changes on Runoff and Low flows using Remote sensing", Journal of Hydrology, 2009,ASCE, Vol-14, pp. 575-587.

[11] V. Bagarello and M. Iovino, "Testing the BEST procedure to estimate the soil water retention curve," Geoderma, 2012, vol. 187188, pp. 67-76. 